DOI: https://doi.org/10.24867/11GI01Gostovic

\title{
KORPORATIVNA DRUŠTVENA ODGOVORNOST U FUNKCIJI UNAPREĐENJA IMIDŽA BRENDA
}

\section{CORPORATE SOCIAL RESPONSIBILITY IN IMPROVING BRAND IMAGE}

\author{
Uroš Gostović, Fakultet tehničkih nauka, Novi Sad
}

\begin{abstract}
Oblast - INŽENJERSKI MENADŽMENT
Kratak sadržaj - Eko-marketing $i$ korporativna društvena odgovornost ima izuzetno velik značaj danas, a trendovi nam pokazuju da će ove teme postati još relevantnije u budućnosti. Iako se ulaganje u društveno odgovorno poslovanje u prošlosti smatralo uzaludnim ulaganje, danas je očigledno, da su ovakve investicije mudra odluka kako dugoročno imaju pozitivan uticaj na imidž kompanije u društvu. Cilj svake kompanije jeste profitabilnost, ali se danas stvara sve veći pritisak na kompanije da se bavi pitanjima od značaja za društvo $i$ okolinu. Iz tog razloga, sve više kompanija, u okviru svoje strategije, ima deo posvećen društvenoj odgovornosti. Ukoliko se rešavanju nekog društvenog problema pristupi sistematično i ulože neophodni resursi, kompanija može očekivati pozitivne rezultate na duge staze u smislu povećanja reputacije i boljeg imidža u društvu kompaniju.
\end{abstract}

Ključne reči: Eko-marketing, korporativno društvena odgovornost, imidž brenda

\begin{abstract}
Eco-marketing and corporate social responsibility $(C S R)$ is already important today, and it will only become more and more relevant in the future. Investing money in CSR projects in the past was considered a waste of money, but it is obvious today, that investing in CSR project is a wise decision as it affects company image in the society. The main goal of every company is to be profitable, but the pressure companies experience to tackle problems regarding problems in society and the environment is only rising. This is why many companies are dedicating part of their corporate strategies to CSR.
\end{abstract}

Keywords: Eco-marketing, corporate social responsibility, brand image

\section{UVOD}

Živimo u svetu konzumerizma, gde proizvodi imaju znatno kraći životni vek nego što je to bilo pre samo 20 godina, a ljudi mnogo lakše i brže zamenjuju jedan proizvod drugima. Kupci su u godinama koje su dolazile postajali sve više informisani i zahtevni.

Skoro svaka industrija ima neki vid društveno odgovornog poslovanja na koji iskazuje da se ona brine o životnoj sredini i da na neki način daje svoj doprinos zajednici.

\section{NAPOMENA:}

Ovaj rad proistekao je iz master rada čiji mentor je bila doc. dr Jelena Spajić.
Izgradnja brenda i stvaranje lojalnosti kupaca u vreme kada je tržište postalo globalno i kada je kupcima skoro svaki proizvod udaljen nekoliko klikova zaista predstavlja izazov. Stvaranje brenda sa kojim se kupci mogu poistovetiti i povezati je ono što se pokazuje kao recept za uspeh. Daje im se dodatna vrednost koju jedan brend nosi sa sobom. Od projekata u kojima se pomaže i vraća zajednici, izdvajanje dela prihoda od svakog proizvoda, pomaganje marginalizovanim grupama, projekti koji se bave zaštitom životne sredinu i sl. jesu prilika u kojoj kompanije mogu da pokažu svoju posvećenost određenom cilju koji se poklapa sa vrednostima koje imaju i njihovi potrošači. Na ovaj način one grade vezu za svojim potrošačima, ali i zajednicom u kojoj se nalaze.

\section{EKO-MARKETING: KONCEPT I ZNAČAJ}

U današnje vreme je već poznat termin eko-marketinga. Kada se govori o njemu uglavnom se misli na promociju proizvoda koji su eko. Pojmovi kao reciklaža, mogućnost ponovne upotrebe, sigurno po ozon i sl. su izuzetno popularni i oni koje potrošači povezuju sa eko-marketingom. Međutim, eko-marketing predstavlja mnogo širi pojam nego to se to čini na prvi pogled. Može se povezati sa fizičkim proizvodima koji se prodaju potrošačima ali i sa samim uslugama. Pojam eko-marketing obuhvata širok spektar aktivnosti poput modifikacije proizvoda, proizvodnih procesa, pakovanja, promene u dizajnu kao i promociji [1].

Ulaskom u 21. vek, saznanje o globalnom zagrevanju i posledicama koje dolaze sa njim, uticalo je na to da ovaj pojam postaje izuzetno vidljiv i opšte prihvaćen. To je naravno podstaklo mnoge kompanije u smeru toga da njihovi proizvodi i usluge postanu naklonjeni ka ekologiji, odnosno zaštiti životne sredine. Sve ovo dešavalo se zajedno sa donošenjem Kyoto protokola koji je podstakao razvoj čistih i zelenih tehnologija kao i koncepta čistog mehanizma razvoja (Clean Development Mechanism) koji je stvoren kako bi se sprečila ekološka katastrofa [2].

Nešto novije viđenje i definisanje eko-marketinga je dao Grant. Njegovo mišljenje je da je glavni cilj ekomarketinga da edukuje ljude o tome zašto je bitno brinuti i kupovati "zelene proizvode" koji čuvaju okolinu, kako marketing ima moć da menja navike ljudi, a samim tim i navike potencijalnih potrošača [3].

Ono što se promenilo u poslednjih nekoliko decenija jeste upravo pritisak koje društvo, države, razne organizacije i 
sl. stavljaju pred kompanije. Od njih se očekuje odgovorno ponašanje prilikom poslovanja. Društvena odgovornost kompanije postala je izuzetno značajna $u$ ovom modernom vremenu gde se konstantno radi na tome da kompanije kao jedna celina minimizuje svoj negativan uticaj koji ima na društvo i okolinu, ali i na pojedinačne grupe ljudi i individue. Kada pogledamo situaciju na globalnom nivou možemo reći da se kompanije nalaze pod sve većom lupom u smislu na koji način one utiču na okolinu. Svest potrošača se potpuno promenila, pogotovo kada gledamo njihove obrasce ponašanja i kupovine, što može značajno da utiče na profitabilnost kompanije. Uz sve to treba dodati i činjenicu da su kupci postali zahtevniji i da vrše pritisak na kompanija da menjaju i transformišu svoje poslovne aktivnosti kako bi smanjili svoj uticaj na okolinu [4].

\section{KORPORATIVNA DRUŠTVENA ODGOVORNOST}

Potrošači su promenili svoje viđenje proizvoda i usluga, ali i način na koji kompanije treba da posluju. Iz tog razloga su se promenili razni zakoni, regulative, pojavile su se najrazličite organizacije, pojedinici i sl. Svi oni zalažu se za određeno ponašanje kompanije koje se u današnjem vremenu ne može izbeći ukoliko kompanija želi da posluje uspešno [5].

Hopkins definiše korporativno društvenu odgovornost $\underline{\mathrm{kaO}}$

Pažnju s kojom se na etičan i društveno odgovoran način odnosimo prema interesno-uticajnim grupama koje se nalaze izvan, ali $i$ unutar organizacije. Cilj društvene odgovornosti je da uz očuvanje profitabilnosti istovremeno omogući stvaranje visokih standarda života za interesno-uticajne grupe izvan i unutar preduzeća [6].

Evropska Unija, tačnije Evropska komisija je takođe u svojim smernicama za politiku društvene odgovornosti definisala društvenu korporativnu odgovornost kao koncept prema kome preduzeće na dobrovoljnom principu integriše brigu o društvenim pitanjima i zaštiti prirodnog okruženja u svoje poslovne aktivnosti i odnose sa stejkholderima (vlasnicima, akcionarima, zaposlenima, potrošačima, dobavljačima, vladom, medijima i širom javnošću) [7].

Koncept korporativne društvene odgovornosti je mnogo širi nego što se to inicijalno može shvatiti. Odnosno, on ne predstavlja samo oblik korporativne filantropije, koja podrazume recimo doniranje novca u neke svrhe, već predstavlja mnogo širi pojam. U tom slučaju ne možemo posmatrati preduzeće kao izolovanu ekonomsku jedinicu čiji je jedini cilj ostvarivanje profita, već kao socioekonomski entitet koji ima više ciljeva i uvažava širi krug interesa kroz razumevanje okruženja u kom se nalazi. uticajem poslovanja kompanije i predstavljaju ciljne grupe preduzeća.

\subsection{Razlozi primene društveno odgovornog ponašanja}

Društveno odgovorno ponašanje kreira poverenje između poslovnog sveta i zajednice i predstavlja vid ulaganja u budućnost. Ono ne predstavlja rasipanje novca, već pametno ulaganje u budućnost.
U razvijenijim zemljama možemo primetiti da društvena odgovornost postaje sve veći faktor koji na koji potrošači obraćanju pažnju pri odabira brenda. Porter i Kramer sa druge strane ukazuju na to da pored direktnog doprinosa društveno odgovornog poslovanja preduzeća postoji i povratni indirektan uticaj, posredstvom društvene zajednice. Pošto su privreda i društvo međusobno povezani i uslovljeni elementi, razvoj jednog elementa povratno pozitivno utiče na drugi i obrnuto. Na primer, ako preduzeća pomažu sprovođenje projekata za unapređenje obrazovnih sistema određenog društva, doprineće unapređenju obrazovne strukture stanovništva, ona povratno doprinosi povećanju uspešnosti njihovog poslovanja zahvaljujući ponudi kvalifikovanije radne snage [8].

\subsection{Ciljevi i nivoi korporativne društvene odgovornosti}

U okviru društvene korporativne odgovornosti postoje tri elementa koja su prikazana na slici 1 kao ključni ciljevi svake KDO aktivnosti [9]:

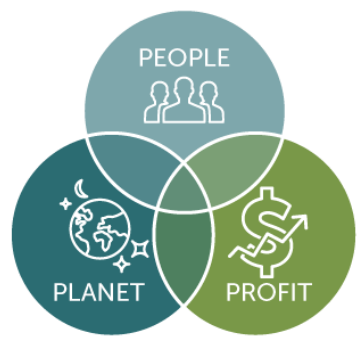

Slika 1. Elementi korporativne društvene odgovornosti [9]

Uravnoteženjem finansijskih, socijalnih i ekoloških ciljeva, stvara se sinergija koja može, i za kompaniju i za društvo, da predstavlja generator dugoročnog razvoja [10]. Na osnovu toga je i definisan pristup poznatiji kao Trostruki krajnji rezultat (Triple bottom line) koji se dodatno naziva i Tri stuba eko-marketinga (Three pillar 3P-People, Planet and Profit).

Jedna od ključnih odlika korporativne društvene odgovornosti jesu i elementi ovog koncepta predstavljeni grafički kao piramida korporativne društvene odgovornosti koja se sastoji iz četiri nivoa: ekonomski, zakonski, etički i filantropski nivo kao što je to i prikazano na slici 2:

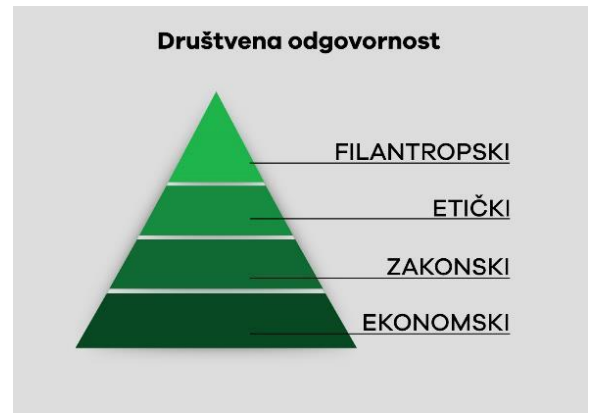

Slika 2. Piramida korporativne društvene odgovornosti [11] 


\subsection{Društveno odgovorno poslovanje u Srbiji}

Tokom prethodnih decenija primećuje se porast i trend društveno odgovornog ponašanja, što ukazuje na to da su kompanije zaista spremne da daju više novca i ulože trud kako bi se neki problem rešio. Kada se radi o društveno odgovornim projektima u Srbiji, kompanije najviše ulažu u sledeće oblasti [12]:

\section{Obrazovanje / $94 \%$}

2. Zaštita životne sredine / $76 \%$

3. Kultura i umetnost / $65 \%$

4. Humanitarna pomoć / $65 \%$

5. Sport $/ 59 \%$

6. Inkluzija / $53 \%$

7. Zapošljivost / 53\%

8. Preduzetništvo / 53\%

9. Zdravi životni stilovi / 35\%

10. Aktivno starenje / $29 \%$

11. Ljudska prava / $12 \%$

12. Drugo, u tesnoj vezi sa osnovnim biznisom / $12 \%$

\subsection{Korporativna društvena odgovornost i brend iskustvo}

Korporativno društvenu odgovornost možemo posmatrati i kao sve značajniji element brenda.

Zahvaljujući dosledno realizovanom konceptu korporativne društvene odgovornosti i adekvatnoj komunikaciji sa ciljnim grupama obogaćuje se karakter brenda [13], odnosno sam brend postaje prepoznatljiviji. Snažan brend pored nekih osnovnih stvari da ima dobar proizvod koji zadovoljava potrebe kupaca, mora i da obuhvati neke od esencijalnih vrednosti poput pouzdanosti, poštenja i integriteta [10].

Društveno odgovorno ponašanje u svesti potrošača stvara pozitivnu sliku o brendu, kako realizovanje takvih projekata i aktivnosti pokazuje da kompanija ima karakter, ali isto tako pokazuje predanost da će svojim kupcima da pruži najbolji kvalitet i uslugu uz poštovanje njih i njihovih vrednosti.

Svi ovi napori na kraju pozitivno utiču na sliku brenda $u$ svesti potrošača [14].

\section{POJMOVNO ODREĐENJE BRENDA}

Sa razvojem tržišta i pojavom novih trendova, kao i evolucijom potrošačkih želja i potreba, razvijao se i sam koncept brenda.

Brend se definiše i kao skup očekivanja, sećanja, priča $i$ odnosa koji svi zajedno utiču na odluku potrošača da u trenutku izbora prednost daju jednom proizvodu (ili usluzi) u odnosu na drugi [15].

\subsection{Uloga i značaj brenda}

U zavisnosti od toga na koji način se brend sagledava, odnosno koliko široko ili usko, od toga zavise i uloge koje on ima, odnosno fukcije, ali se u literaturi najčešće sagledava kroz tri funkcije, a one su predstavljene na sledeći način (Slika 3):

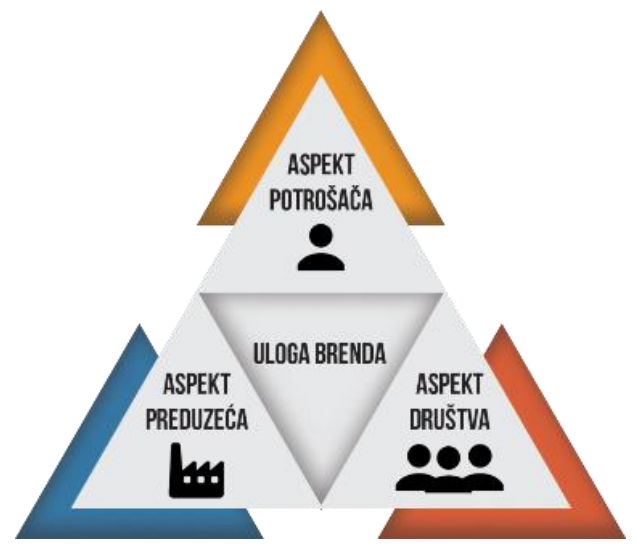

Slika 3. Uloga brenda [10]

\section{Aspekt potrošača}

Kada se prvi put pojavio pojam brenda, za potrošače je označavao samo određeni znak pomoću koga su oni prepoznavali proizvod ili uslugu koja ima se nudila. Nakon samog razvoja brenda i širenje okvira šta to sve brend predstavlja, možemo ga vezivati takođe kao i priliku da potrošač pokaže svoj stil, osećaj, status kao i da dobije osećaj pripadnosti i uključenosti u određenu društvenu grupu.

\section{Aspekt preduzeća}

Pomoću brenda se može povećavati ugled na tržištu, ostvarivati profit kao i širiti tržište na kome već posluje. Sa stanovišta kompanije, brend je i cilj $i$ sredstvo [10]. Suštinski brend je taj koji pokreće preduzeće i koje mu pomaže da se bori sa stalnom konkurencijom, na izuzetno velikom i hiperaktivnom tržištu koje danas postoji.

\section{Društveni aspekt}

U današnje vreme brend pored toga što se vezuje za proizvode i usluge, potrošače, kompanije, on ima $i$ društveni aspekt. Zemlje su u stalnoj komunikaciji, razmenjuju političke, sportske, zabavne, kulturne i mnoge druge poruke koje predstavljaju ideju o tome šta one kao jedna celina žele, u šta veruju i šta osećaju. Zadatak jedne države jeste da sintetizuje, uobliči i iskomunicira sve te poruke i da izgrađuje određeni ugled, da iskomunicira šta to ona sve može da ponudi, koji je njen potencija i da na taj način stvori brend od sebe.

\subsection{Efektivno brend komuniciranje}

Da bi brend komuniciranje bilo efektivno ono zahteva strategiju koja inkorporira vrednosti brenda, a sve to $u$ cilju ispunjenja socijalno-psiholoških zahteva poslovnih kupaca, isto koliko i njihovih racionalnih zahteva [10].

Sa aspekta generalne svrhe komunikacionih aktivnosti, brend komuniciranje se može posmatrati na tri nivoa:

- Korporativne komunikacije

- Marketing komunikacije i

- Dijaloške komunikacije

Sama podela izvršena je u odnosu na koga je proces komuniciranja usmeren. Ukoliko je pažnja usmerena na samu organizaciju radi se o korporativnim komunikacijama, ako je akcenat na proizvodima onda se radi o marketing komunikacijama, a ukoliko se gradi lični kontakt između kompanija na industrijskom tržištu, radi se o dijaloškoj komunikaciji. Uspeh dijaloške 
komunikacije povezan je i direktno zavisi od toga koliko je efektivna interna komunikacija, ali je takođe povezana sa interaktivnom komunikacijom.

\section{ZAKLJUČAK}

Kroz aktivnosti društveno odgovornog ponašanja, kompanija ima značajne implikacije na društvo kao i na životnu okolinu. Ono što možemo primetiti kroz istoriju jeste da se svest o tome kako i na koji način se kompanije ophode prema ljudima, ali i životnoj sredini, povećava. Činjenica je da društvo više ne želi da se kompanije prema njemu, a ni okolini, ophode na loš način. Osim pritiska koji društvo stavlja na kompanije, postoji i velika količina pritiska sa strane zakona i od neproftinih organizacija koje se bore za različite ciljeve.

Eko-marketing je efektivna strategija svake kompanije i ukoliko se koristi na pravi način, može doneti izuzetno dobre rezultate. Međutim, ukoliko se određene stvari promovišu kao ,zelene“ a one to ustvari nisu ili ukoliko kompanija zaista ne stoji iza onoga što govori, to u očima potrošača izaziva negativne efekte. $U$ tom slučaju kompanija u potpunosti može da izgubi lojalnost svojih potrošača. Kako bi se sprečili takvi događaji, kompanija mora da razmišlja strateški. Danas skoro i da ne postoje velike kompanije koje u okviru svoje strategije nemaju deo koji se tiče društveno odgovornog poslovanja. Ovo predstavlja zaista veliki korak za kompanije, kako se u prošlosti kompanije nisu ozbiljno bavile društveno odgovornim poslovanjem. Danas, kompanije to ipak rade na drugačiji način. Biraju na koji način će svoje resurse utrošiti da bi rešili određeni problem u društvu.

Društveno odgovorni projekti utiču na razvoj zajednice $u$ kojoj se kompanija nalazi, što dovodi do prosperiteta zajednice $\mathrm{i}$ na duge staze ima pozitivan uticaj $\mathrm{i}$ na kompanije. Ono što možemo zakjučiti jeste da je društveno odgovorno ponašanje trend koji ne jenjava, te da će u budućnosti pritisak na kompanije da se ponašaju odgovorno biti sve veći. Kompanije neće imati izbora, nego da se ponašaju odgovorno prema svojoj sredini i društvu bilo da je to nešto u šta one zaista veruju ili ne.

\section{LITERATURA}

[1] A. Sarkar, "Green Branding and Eco-innovations," Asia-Pacific Journal of Management Research and Innovation, p. 39-58, 2012.

[2] “https://unfccc.int/kyoto_protocol," 2008. [Online]. Available:

https://unfccc.int/sites/default/files/08_unfccc_kp_re f_manual.pdf.

[3] J. Grant, The green marketing manifesto., England: John Wiley \& Sons Ltd. , 2007.

[4] E. Olson, "Business as environmental steward: The growth of greening.," Journal of Business Strategy, p. 4-13, 2009.

[5] I. Đurović and D. Ranđić, 2011. [Online]. Available: http://www.cqm.rs/2011/FQ2011/pdf/38/14.pdf.

[6] M. Hopkins, What is Corporate Social Responsibility all about, Chichester, UK: John Wiley\&Sons, Ltd, 2005.
[7] Europan Commission, Corporate social responsibility: A business contribution to sustainable development, Luxemburg: Office for Official Publication of the European Communities, 2002.

[8] M. Porter and M. Kramer, Strategy and Society: The Link Between Competitive Advantage and Corporate Social Resposibility, Hardward Business Review, 2006.

[9] A. Savitz and K. Weber, The Triple Bottom Line: How Today's Best-Run Companies Are Achieving Economic, Social And Environmental Success- And how You can Too., San Francisco, CA: JosseyBass., 2006.

[10] S. T. Nikolić, J. Stanković and A. Dejanović, Brend menadžment:Savremena a(tra)kcija, Novi Sad: FTN Izdavaštvo, 2015.

[11] A. B. Carroll, A Three-Dimensional Conceptual Model of Corporate Performance, Academy of Management Review, 1979.

[12] Smart Kolektiv, 2013. [Online]. Available: http://odgovornoposlovanje.rs/wpcontent/uploads/2015/03/FOP_Rezultati2013_Ebros ura.pdf.

[13] C. Mark-Herbert and C. von Shantz, "Communication Corporate Social Responsibility Brand Management," Electronical Journal of Business Ethics and Organization Studies, pp. 4-11, 2007.

[14] I. Maignan, O. Ferrell and G. Hult, "“Corporate citizenship: cultural antecedents and business benefits," 1999, pp. 455-469.

[15] S. Godin, "Brand," 13 December 2012. [Online]. Available: http://sethgodin.typepad.com. [Accessed 6 Jun 2018].

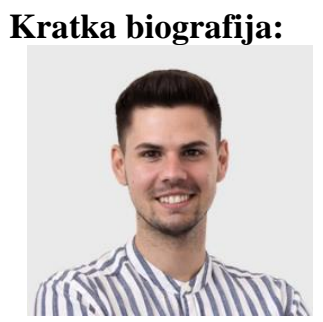

Uroš Gostović rođen je u Novom Sadu 1995. god. Master rad na Fakultetu tehničkih nauka iz oblasti Inženjerski menadžment odbranio je 2020.god.

kontakt: urosgostovic@gmail.com 